\title{
DOS TITULOS DE GREDITO NO DIREITO BRASILEIRO
}

\author{
"Sempre e dapertutto insomma la \\ storia ci dimostra che lo sviluppo della \\ proprietá mobile é parallelo a quello \\ della libertá individuale." (Bruschettini, \\ Titoli al portatore, introducção).
}

PARTE GERAL

(Capitulo inedito de um livro em preparação.)

Da natureza juridica dos titulos de credito.

$\left.1 .^{\circ}\right)$ E' operação de credito toda aquella pela qual se fornece uma prestação, na esperança de uma contraprestação futura: um intervallo de tempo entre as duas prestações é essencial a toda operação de credito. (Vivante).

O tituko entregue pelo devedor ao credor, e representativo da relação de direito estabelecida entre elles, é o titulo de credito.

$\left.2 .^{\circ}\right) \quad$ Só é propriamente titulo de credito aquelle que o devedor emitte sobre a base da confiança que inspira a sua solvabilidade, ou antes, o seu credito pessoal.

Se o titulo tem uma garantia qualquer real, como os warrants, ou os conhecimentos de mercadorias, não será propriamente um titulo de credito, porque não foi emittido sobre a base exclusiva do credito pessoal do devedor, mas sobre a mercadoria a este pertencente. 
3.) Os titulos de credito poder ser publicos ou privados. Publicos são os emitidos pelo poder publico, como as apolices federaes ou estadoaes, e as letras das camaras municipaes. Todos os outros titulos de credito são privados.

$\left.4 .^{\circ}\right)$ Entre estes ultimos ha alguns que tem uma garantia especial sobre certos bens do devedor. Taes são as obrigações ao portador emittidas pelas sociedades anonymas, quando garantidas por hypotheca. Dahi a divisão dos titulos em - titulos de credito pessoal, e titulos de credito real.

$5^{\circ}$ ) O titulo de credito não tem valor intrinseco. E' o que o distingue da moeda. Por isso mesmo não tem valor liberatorio. $\mathrm{O}$ titulo de credito não representa mais que a prestação devida pelo emissor ao seu portador. Conseguintemente, é sempre a representação de uma relação de direito entre devedor e credor, consubstanciando o direito creditorio do segundo contra o primeiro. E' esse o seu unico valor.

$6^{\circ}{ }^{\circ}$ O fim principal dos titulos de credito é circularem com facilidade e segurança. Dahi o caracteristico, que os distingue - a litteralidade, a qual consiste na necessidade da exhibição do titulo, para o exercicio do direito nelle declarado.

$7^{\circ}$ ) Isto não quer dizer que o direito creditorio esteja incorporado no titulo, como pretendem os partidarios da theoria da incorporação, e como diz o projecto do Codigo Commercial de Inglez de Souza, art. 390. O titulo de credito não é mais do que o meio de prova da relação de direito existente entre o emissor e o portador, mas para poder exercer os direitos declarados no titulo e assegurados na lei, é indispensavel que o credor exhiba o titulo.

8. ) Para que os titulos de credito circulem com facilidade e segurança, a lei simplificou o mais possivel o 
processo de sua transmissão, e creou um principio novo, - da inopponibilidade das excepções, pelo qual o devedor só póde oppor ao portador do titulo as excepções que lhe forem pessoaes, não aquellas que cabiam contra o portador antecedente.

9. ) Os titulos de credito podem ser nominativos, $\dot{a}$ ordem e ao portador. Os primeiros são aquelles que de. signam nominativamente o titular do direito creditorio, e só podem ser transferidos por um termo lavrado em livro competente existente em poder do emissor, termo em virtude do qual o emissor emitte um novo titulo a favor do cessionario. Taes são as apolices da divida publica, federal ou estadoal.

$10 .^{\circ}$ ) Titulos á ordem são os titulos cambiaes - a letra de cambio, a nota promissoria e o cheque, e todos os outros que, embora não cambiaes, só podem ser transferidos por endosso.

11. ) Titulos ao portador são todos aquelles transmissiveis por méra tradicção manual. Taes são as debentures ou obrigações ao portador, emittidas pelas sociedades anonymas.

$\left.12 .^{\circ}\right)$ Em relação a todos elles se nota a connexão do titulo com o credito, isto é - o direito creditorio não pode ser exercido sem a exhibição do titulo.

13. ${ }^{\circ}$ Todos elles resultam de uma convenção entre o devedor e o primeiro credor. Sua origem é, portanto. contractual.

14..$^{\circ}$ Uma vez, porem, transferido o titulo pelo primeiro portador, qual a natureza da relação juridica entre o devedor e os portadores subsequentes? O direito destes é um direito proprio ou derivado? Si é derivado, como se o conciliar com a inopponibilidade das excepçóes? São questões que serão estudadas quando tratarmos da tran:- 
missão dos titulos de credito. Agora diremos apenas que a relação é sempre pessoal entre o devedor e o portador do titulo nominativo.

15. ${ }^{\circ}$ Em relação, porem, aos titulos á ordem e ao portador, a relação só é pessoal entre o devedor e o primeiro portador. Uma vez, transferido o titulo, o devedor já não conhecerá o seu portador. Verifica-se, portanto, que no titulo nominativo a relação é sempre um puro vinculo pessoal entre duas pessoas determinadas, como era a obrigação romana.

16. ${ }^{\circ}$ Em relação, porem, aos titulos á ordem e ao portador, a relação continúa a ser pessoal, não já, porem, entre duas pessoas determinadas, o devedor e aquelle com quem esta contractou, mas sim o devedor, que persiste o mesmo, e qualquer outro a quem o primitivo credor tenha cedido o titulo, ou outro portador subsequente. A pessôa do credor é, portanto, generica e não individual.

17. ) Isto quer dizer que nos titulos á ordem e ao portador o elemento patrimonial sobrepujou o pessoal. A conveniencia de facilitar a prompta e segura circulação dos titulos assim o exigiu, para que os titulos preenchessem o seu fim economico, pois que só pela possibilidade de uma continua e segura substituição do credor, é que os titulos de credito assumiriam a feição de bem economico.

18. ) Para justificarem esta substituição continuii da pessoa do credor, sem prejuizo do direito deste contra o devedor primitivo, imaginaram os escriptores allemães a theoria da divida abstracta, pela qual o devedor deve ao titulo, sem necessidade de indicar a causa da obrigação. Nesta ordem de idéas, houve escriptores que foram até a theoria chamadà da personificação, pela qual o titulo é o verdadeiro credor, não passando o portador de um seu representante. 
19..$^{\circ}$ Estas doutrinas estão hoje abandonadas. Não ha dividas abstractas, pela simples razão de que é impossivel separar os actos humanos da causa que os determina. Mais absurdo ainda é attribuir a uma cousa, e especialmente uma cousa movel, a qualidade de titular de um direito creditorio.

$20 .^{\circ}$ ) Com o fim egualmente de justificar o direito do portador contra o devedor, quando este não conhece ainda quem seja o seu credor, imaginou-se modernamente a theoria do acto unilateral, pela qual a divida existe tão somente pelo acto do devedor, creando o titulo de divida.

$21 .^{\circ}$ ) Esta theoria parece ter sido adoptada pelo nosso Codigo Civil, cujo titulo $6 .^{\circ}$ do livro terceiro se inscreve —- "das obrigaçóes por declaração unilateral da vontade."

22. ) Não ha, porem, nem pode haver obrigação por acto unilateral do devedor. A obrigação é sempre um vinculo que prende o devedor ao credor. Não ha, portanto, nem pode haver obrigação sem que exista o titular do direito creditorio. A obrigação é sempre uma relação de direito, um laço obrigacional, impossivel de existir, portanto, sem a co-existencia dos dois termos da relação - o titular activo e o titular passivo da obrigação.

23. ) O que diz o Codigo Civil no art. 1506 é que a obrigação pode existir sem que o devedor conheça a pessoa do credor, isto é, por emissão involuntaria do tititulo, quando este tenha sido perdido pelo devedor, ou lhe haja sido furtado, e o inventor ou o ladrão o tenha transferido a um portador de boa fé. Nesse caso o laço obrigacional se forma entre o emissor e esse portador de boa fé. Não ha, portanto, obrigação por acto unilateral do devedor.

$\left.24 .^{\circ}\right) \quad 0$ que resulta do art. 1506 é que a emissão do titulo pode ser voluntaria ou involuntaria. Será volunta- 
ria quando o titulo for entregue pelo emissor ao primeiro portador. Será involuntaria quando o titulo tiver sido furtado, ou perdido pelo devedor, e for parar ás mãos de um portador de boa fé. Mas, a emissão, isto é, a posse legitima do titulo por um portador de boa fé, é indispensavel para se formar o laço obrigacional.

25. ) A theoria da emissão é, portanto, a nossa theoria legal, em materia de titulos de credito. Ora, tal theoria tem por base ou fundamento contracto, o accordo de vontades entre o credor e o devedor. E' incompativel, portanto com a creação da obrigação por acto unilateral do devedor.

26..$^{\circ}$ O que o devedor cria por acto unilateral é o titulo, mas não a obrigação. Antẹs de emittida, voluntaria ou involuntariamente, o titulo está creado, mas não representa obrigação alguma do seu creador. Uma nota promissoria subscripta por mim, emquanto permanece em meu poder, isto é, antes de entregue ao credor, não representa obrigação alguma de minha parte.

27.') E tanto é assim que, emquanto o titulo está em meu poder, eu o posso destruir. Que obrigação, que vinculo obrigacional é esse que eu sosinho o posso crear, eu sosinho o posso destruir? A doutrina da obrigação resultante de um acto unilateral do devedor nasce, portanto, de uma confusão entre a creação e a emissão do titulo. O titulo é creado pelo devedor, mas antes de emittido é um papel sem valor algum juridico. Só adquire esse valor, só passa a ser o titulo representativo de uma relação juridica depois de entregue a um portador de bôa fé.

$\left.28 .^{\circ}\right)$ Convem distinguir entre a posse e a propriedade do titulo de credito. $\mathrm{O}$ simples possuidor pode receber a prestação devida pelo devedor, e este pagando mesmo ao possuidor de má fé fica exonerado da obrigação, salvo si agir com dolo. $\mathrm{O}$ direito, porem, de exigir do deve- 
dor o pagamento da prestação só compete ao legitimo proprietario do titulo, ou a quem directamente o represente. E' o que se contem expressamente no art. 1506 do Codigo Civil.

29..$^{\circ}$ A nossa theoria legal, portanto, em materia de transmissão de titulos de credito, é a theoria da propriedade. Não vigora em nosso direito a regra francesa - en fait de meubles possession vaut titre. E' o que dispõe expressamente o art. 622 do Codigo: - "Feita por quem não seja proprietario, a tradicção não alheia a propriedade."

$\left.30 .^{\circ}\right)$ A acquisição com boa fé, pelo nosso direito, não é então, sufficiente para conferir a propriedade dos bens moveis? Parece que não, pelo art. 521 do Codigo Civil, o qual attribúe ao legitimo proprietario de titulos perdidos ou furtados, o direito de os reinvindicar do poder de quem os detiver, ainda que seja um possuidor de boa fé.

$\left.31 .^{\circ}\right)$ Mas, cumpre advertir que essa disposição do Codigo Civil não se concilia com o art. $39 \S \S 2$. da lei 2044 de 31 de Dezembro de 1908, pelo qual o possuidor da letra de cambio, só no caso de má fé na acquisição, é que pode ser obrigado a abrir mão do titulo.

$32 .^{\circ}$ Um escriptor recente, Ponts de Miranda, em seu livro - Titulos ao Portador procurou resolver a contradicção, sustentando que no caso do art. 521 do Codigo Civil trata-se de uma reinvindicação apenas possessoria, como a do art. 1007 do Codigo Civil allemão.

$\left.33 .^{\circ}\right)$ Tal opinião é injustificavel. 0 direito allemão adopta a regra - en fait de meubles possession vaut titre -, que o nosso repelle. Pelo direito allemão os titulos ao portador são reinvindicaveis, pelo nosso são reinvindicaveis. Por isso mesmo, a acção de reivindicação, pelo nosso direito, só cabe ao dono, como, aliás, diz ex- 
pressamente o Codigo no art. 521, na alinea. No direito allemão, a reinvindicação do art. 1007 é posessoria, justamente porque nesse direito, em relação aos moveis, $a$ posse vale titulo. Assim, é inutil discutir o dominio dos moveis. Mas, tal disposição não se applica aos titulos ao art. 1007 E' uma incongruencia, portanto, querer ao portador, como o.Codig Civil allemão diz expressamente titulos ao portador, no direito brasileiro, a reinvindicação possessoria do art. 1007 do Codigo allemão.

$\left.34 .^{\circ}\right) \quad 0$ que é preciso é distinguir as relações do emissor com o portador dos titulos, das relações dos portadores entre si. As primeiras se regulam pelo criterio da posse. Basta ser possuidor do titulo para o emissor ter o direito de pagar ao portador as prestações correspondentes. Entre os successivos portadores, porem, o criterio regulador é o da propriedade, pois só o legitimo dono, provando o seu dominio, é que poderá reinvindicar do portador os titulos que este detiver.

$\left.35 .^{\circ}\right) \quad 0$ traço fundamental do titulo de credito é ser um titulo de circulação. Taes são os titulos á ordem e os titulos ao portador. Por isso protege por todos os meios, procurando sempre tornar mais facil e segura, a circulação dos titulos. E' o que se deduz do art. 1506 do Codigo Civil, pelo qual "a obrigação do emissor subsiste, ainda que o titulo tenha entrado em cinculação, contra a sua vontade." Ergo, aquelle que adquirir de boa fé um titulo ao inventor ou ao ladrão, sempre que a victima da perda ou furto fôr o emissor, tornar-se-á legitimo dono do titulo adquirido. E' inquestionavel, portanto, que nesse caso a acquisição com boa fé é sufficiente, para conferir dominio ao adquirente.

$\left.36 .^{\circ}\right) \quad J a ́$ a situação não será a mesma quando se tratar de titulos furtados ao seu legitimo dono, ou por este perdidos. Nesse caso, o proprietario desapossado tem c direito, pelo art. 521, de reivindicar os titulos de quem os 
detiver, ainda que seja um adquirente de boa fé. A acquisição com boa fé não confere nesse caso mais que posse do adquirente, posse que lhe dá apenas o direito de receber do emissor a prestação respectiva.

$\left.37 .^{\circ}\right)$ Ao contrario os titulos á ordem e ao portador, os titulos nominativos não são titulos de circulação, mas de collocação de capitaes. Por isso mesmo a lei não protege a sua circulação, com os mesmos cuidados com que o faz em relação aquelles outros titulos, $\mathrm{Na}$ phrase. de Ludovico Mortara, "a lei considerou de interesse publico a facilitação do trafico dos titulos nominativos." Mesmo nos paizes onde vigora o principio de que - a posse vale titulo. - , tal principio não se applica aos titulos nominativos.

38. ${ }^{\circ}$ Conseguintemente, podemos concluir que o titulo de credito é um documento representativo da relação de direito entre o emissor e o portador, sem cuja exhi. bição o portador não poderá exercer o direito creditorio; documento, portanto, litteral e cujo destino essencial é circular, conferindo sempre ao portador um direito proprio directo e autonomo contra o emissor, pelo que este não pode oppor ao portador quaesquer excepçóes cabiveis contra os portadores antecedentes.

39. ) Mesmo que o titulo tenha sahido do pode: do emissor sem a annuencia deste, desde que foi parar ás mãos d'um portador de boa fé, é porque este acceitou a offerta feita pelo emissor e declarada no titulo. Essa acceitação estabelece a relação contractual entre o emissor e o portador desconhecido, de accordo com o principio da agnição estabelecido no art. 1086 do Codigo Civil.

Contractual, litteral, circulante, corporeo e autonomo, taes são os caracteristicos do titulo de credito, cuja natureza juridica fica, assim, perfeitamente determinada.

S. Paulo, Novembro de 1923.

Octavio Mendes. 